\title{
The Effect of Isotopic Composition on the Uncertainty of Routine Metal Mass Concentration Measurements in Ambient Air
}

\author{
Richard J. C. Brown, Sharon L. Goddard, Andrew S. Brown, and Rachel E. Yardley \\ Analytical Science Team, National Physical Laboratory, Teddington, Middlesex TW11 0LW, UK \\ Correspondence should be addressed to Richard J. C. Brown, richard.brown@npl.co.uk
}

Received 20 October 2008; Accepted 9 December 2008

Recommended by Peter Stockwell

The main sources of uncertainty encountered during the analysis of the mass concentration of metals in ambient air as part of the operation of the UK Heavy Metals Monitoring Network are presented. It is observed that the uncertainty contribution from possible variation in the isotopic composition of the sample depends on the element in question, but can be significant (e.g., for $\mathrm{Pb}, \mathrm{Cd}$, and $\mathrm{Hg}$ ). The working curve method for the ICP-MS analysis of metals in solution, with a low resolution, high throughput instrument measuring at one $\mathrm{m} / \mathrm{z}$ ratio per element, relies on the relative abundance of the isotopes under consideration being the same in both the sample and the calibration solution. Calculation of the uncertainty in this analysis assumes that the isotopic composition variation within the sample and calibration solution is limited to a defined range. Therefore, in order to confirm the validity of this quantification methodology and its uncertainty budget, the isotopic composition of the calibration standards used for quantification has been determined. The results of this analysis are presented here.

Copyright (C) 2008 Richard J. C. Brown et al. This is an open access article distributed under the Creative Commons Attribution License, which permits unrestricted use, distribution, and reproduction in any medium, provided the original work is properly cited.

\section{INTRODUCTION}

The general public and the environment can be exposed to several classes of hazardous compounds containing metallic elements which occur naturally or are released by domestic or industrial processes [1]. The total concentration levels of $\mathrm{Pb}, \mathrm{Ni}, \mathrm{As}$, and $\mathrm{Cd}$ allowable in the $\mathrm{PM}_{10}$ fraction of ambient air (particles with an aerodynamic diameter of $10 \mu \mathrm{m}$ or less) are now limited by European legislation [2-4]. In order to enforce this legislation, to measure human and environmental exposure, and to show compliance with limit and target values, the total concentration levels of ambient metals, at multiple sites on nationwide air quality monitoring networks, need to be measured. To this end, nationwide networks for the measurement of a wide range of particulateborne and gaseous pollutants are now well established in many developed countries around the world. NPL currently manages and operates the UK Heavy Metals Monitoring Network (the "network") on behalf of the UK Department for Environment, Food and Rural Affairs (Defra). The "network" consists of 24 monitoring sites around the UK collecting $\mathrm{PM}_{10}$ particulate matter which is then sent back to NPL for the analysis of the mass concentration of $\mathrm{Ni}$, $\mathrm{As}, \mathrm{Cd}, \mathrm{Pb}$, (as required by European legislation) and also $\mathrm{Hg}, \mathrm{Cr}, \mathrm{Cu}, \mathrm{Fe}, \mathrm{Mn}, \mathrm{V}, \mathrm{Zn}$, and $\mathrm{Pt}$ to contribute to longterm UK data sets [5]. Whilst the data quality objectives laid down by the air quality legislation are not especially exacting - the maximum allowable expanded uncertainty for $\mathrm{Pb}$ determination is $25 \%$, and for $\mathrm{Ni}$, As, and $\mathrm{Cd}$ is $40 \%$ - it is still necessary to ensure that these objectives are routinely and consistently met. Additionally NPL also sets a selfimposed maximum measurement uncertainty of $40 \%$ on the nonmandated metals.

To determine the mass concentration of particulatephase metals in ambient air, particles are collected onto air filters which are then digested in acid before being analysed by inductively coupled plasma-mass spectrometry (ICPMS). The ICP-MS is calibrated by a working curve method using matrix matched solutions prepared from commercially available elemental solutions certified for metal mass fraction, and compared with NIST standard reference material (SRMs) by NPL to ensure consistency and accuracy. Whilst 
NPL includes a component of uncertainty to take account of the possibility of the isotopic composition of metals in ambient air varying within natural limits, for a working curve method this assumes that the isotopic composition of the calibration standards being used also falls within this assumed range. If it does not, then an additional uncertainty contribution, or a correction factor, may need to be applied. In order to validate this hypothesis, the isotopic composition of the standards used for these routine analyses requires measurement. This work presents the results of this analysis and the effect of these findings on the uncertainty budget of the measurement. We also present the contributions to overall uncertainty budget from the possible variations in the isotopic compositions of the ambient air samples.

\section{EXPERIMENTAL}

Particulate samples were taken at all sites in the "network" using Partisol 2000 instruments (fitted with $\mathrm{PM}_{10}$ heads) operating at a calibrated flow rate, nominally of $1 \mathrm{~m}^{3} \cdot \mathrm{h}^{-1}$, in accordance with European standard method EN 12341 [6]. Samples were taken for a period of one week [7] onto $47 \mathrm{~mm}$ diameter GN Metricel membrane filters. The analysis for particulate-phase metals took place using a PerkinElmer Elan DRC II ICP-MS, following NPL's UKAS accredited procedure, which is fully compliant with the requirements of European standard method EN 14902 [8] (the EU "reference method" for the analysis of metals in ambient air). Upon arrival at NPL, the filters sampled with particulate matter were cut accurately in half, and each portion digested at temperatures up to $220^{\circ} \mathrm{C}$ using a CEM Mars X microwave. The digestion mixtures used were as follows.

(i) $\mathrm{Hg}$ and Pt: $5 \mathrm{ml}$ of nitric acid and $5 \mathrm{ml}$ hydrochloric acid.

(ii) All other metals: $8 \mathrm{ml}$ of nitric acid and $2 \mathrm{ml}$ hydrogen peroxide.

These digested solutions were then diluted with deionised water (Millipore, Milli Q, Mass, USA) prior to analysis. ICP-MS analysis took place as previously described [9] using at least four-matrix-matched gravimetrically prepared calibration solutions [10] prepared from monoelemental standard solutions (VWR, checked for total elemental composition against the NIST SRM 3100 series). A detector dead time correction was applied [11] and a full span dual detector linearity check was performed in order to minimise any detector nonlinearity [9] since the concentration of different isotopes within the samples may span several orders of magnitude. A quality control standard was repeatedly analysed (after every two solutions), and the change in response of the quality control standard was mathematically modelled to correct for the long-term drift of the instrument. The short-term drift of the ICP-MS was corrected by the use of an internal standards mixture (containing Y, In, Bi, Sc, Ga, and Rh) continuously added to the all samples via a mixing block. Each sample was analysed in triplicate, each analysis consisting of five replicates. For each element, one isotope at one $m / z$ value was chosen and monitored. The mass of each metal in solution (and its uncertainty) was then determined by a method of generalised least squares using XLGENLINE (an NPLdeveloped programme [12]) to construct a calibration curve. The analysis of the isotopic ratios of the calibration standards was performed by determining the blank-corrected intensity at each appropriate $m / z$ ratio. The isotopic composition of the calibration standards was measured by analysing the separate monoelemental standard solutions used to make up the calibration solutions. All the usual corrections for isobaric and polyatomic corrections were applied. The mass fraction of the sum of all isotopes of metal analyte in each standard solution was approximately $1 \mu \mathrm{g} / \mathrm{g}$. All isotopes of the elements of interest were measured, not simply the ones used for quantification. Whilst no additional effort was made to determine additional corrections for isotopes not usually used for quantification by the NPL procedure, additional type-B uncertainty components were included in the uncertainty budget to account for unresolved inaccuracies owing to mass bias and mass discrimination effects, based on conservative estimates from existing literature data [13]. Given the low precision of the measurements, these factors are expected to have a minimal contribution to the overall uncertainty [14]. Uncertainty contributions were also added to account for residual dead time effects and detector nonlinearity. Matrix effects were minimised by the matrix matching of all solutions prior to analysis. Total expanded measurement uncertainties for each analysis are calculated using a full GUM [15] approach and are expressed with a coverage factor of $k=2$ representing the $95 \%$ confidence interval.

\section{RESULTS AND DISCUSSION}

The working curve method for the ICP-MS analysis of metals in solution, with a low resolution, high throughput instrument measuring at one $m / z$ ratio per element relies on the relative abundance of the isotopes under consideration being the same in both the sample and the calibration solution. If this is not the case, a multiplicative bias in the observed results for element $X, \delta_{X}$, will be observed, and is given by

$$
\delta_{X}=\frac{n_{a, \mathrm{cal}} \cdot \sum_{i} n_{i, \mathrm{sam}}}{n_{a, \mathrm{sam}} \cdot \sum_{i} n_{i, \mathrm{cal}}}
$$

where $n_{a \text {,cal }}$ is the amount of isotope $a$ of element $X$ in the calibration standard, $\sum_{i} n_{i, \text { cal }}$ is the amount of all isotopes of element $X$ in the calibration standard, $n_{a, \text { sam }}$ is the amount of isotope $a$ of element $X$ in the sample, and $\sum_{i} n_{i, \text { sam }}$ is the amount of all isotopes of element $X$ in the sample [16]. When the relative abundance of the isotope used for quantification in both the sample and the calibration solution is the same, then $\delta_{X}=1$ and no bias is observed. It is interesting to note that the isotopic composition with respect to the other isotopes not used for quantification has no effect on the measurement. (As and Mn are also measured by the "network," but are monoisotopic and therefore not considered as part of this treatment). 


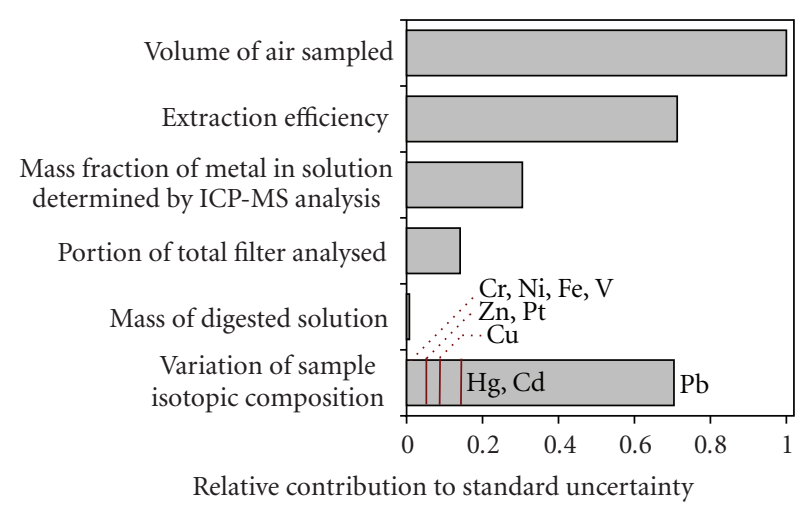

FIGURE 1: Relative contributions to the standard uncertainty of the determination of metal mass concentration in ambient air, as part of the UK Heavy Metals Monitoring Network. This example shows a measurement with an overall expanded uncertainty at the $95 \%$ confidence interval of approximately $20 \%$. The changing uncertainty contribution from the variation in the sample isotopic composition for the different metals measured by the "network" is indicated by the additional lines and labelling on the bottom bar.

Rather than assess the isotopic composition of each individual sample, the uncertainty budget developed for this measurement includes a component of uncertainty to recognise that the isotopic composition of the sample may fall anywhere within the range of natural variations, or the representative isotopic composition, whichever is the larger range [17]. (The actual range of isotopic composition in environmental samples may be considerably narrower [18].) In practice, this assumption assigns $\delta_{X}=1$ but imposes a relative uncertainty on this value equal to the possible range of isotope abundances expected for the isotopes used for quantification. Relatively little detail exists in the literature on the isotopic composition of metals in ambient air particulates. The vast majority of the work that has been published has been on $\mathrm{Pb}$ isotopic composition, where the greatest variation is expected. Determination of isotope ratios has been mostly used as a route to determining the origin of the $\mathrm{Pb}$ sampled, particularly with regard to specific industrial processes or long-range pollutant transport [14]. One study [19] has examined the Pb isotopic composition in deposition in order to compare how this changed before and after the closure of a local $\mathrm{Pb}$ mine. Others studies [20, 21] have used the changing $\mathrm{Pb}$ isotope ratios in ambient particulate matter to demonstrate the seasonal variation longrange transport of pollutants across the Asian continent. Measured $\mathrm{Pb}$ isotope ratios have also been used as a route to determine the changing origins of $\mathrm{Pb}$ emissions in an urban environment during and after the phasing out of leaded petrol [22]. $\mathrm{Cu}$ and $\mathrm{Zn}$ isotopes ratios have been analysed near a large $\mathrm{Zn}$ refinery [23] as a means of determining the origin of metallic ores, and $\mathrm{Sr}$ and $\mathrm{Nd}$ isotope ratios have been used in the discrimination of emissions from various industrial sources and traffic emissions, respectively [24]. In all cases, the observed ranges of the isotopic compositions fell well within the natural ranges predicted [17] and these natural ranges have been used to construct the uncertainty

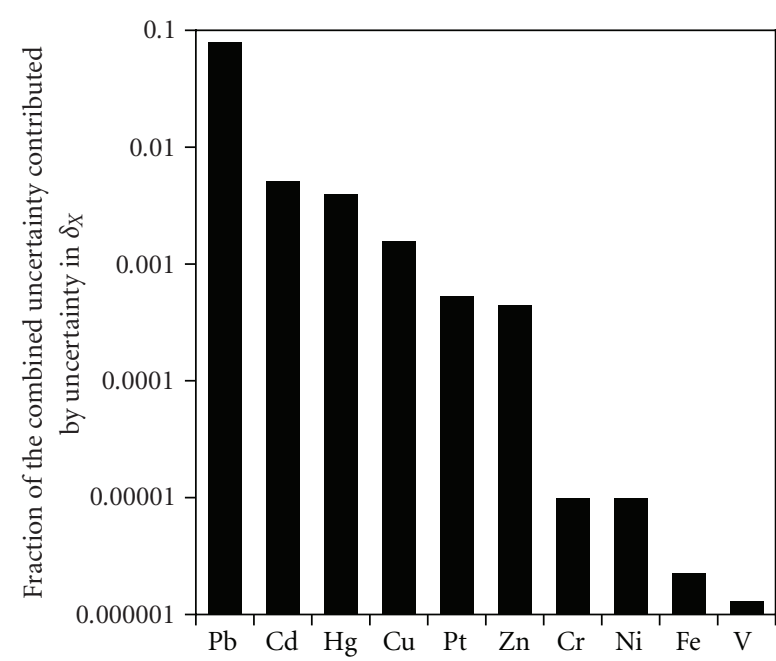

FIGURE 2: The fraction of the overall measurement uncertainty for each metal contributed by the uncertainty in $\delta_{X}$.

budget presented in this paper. Moreover, when the isotopic composition of samples under consideration in this study has been measured periodically, the abundance of the isotope used for quantitation has always been well within these ranges as well [25]. The major contributions to the overall measurement uncertainty for the determination of the mass concentration of metal in ambient air are shown in Figure 1.

As can be seen, the contribution from the possible variation in the isotopic composition of the sample is strongly dependent on the element being determined. This contribution is very significant for $\mathrm{Pb}$, significant for $\mathrm{Hg}$, and $\mathrm{Cd}$, less significant for $\mathrm{Cu}, \mathrm{Zn}$ and $\mathrm{Pt}$, and negligible for $\mathrm{Cr}$, $\mathrm{Ni}, \mathrm{Fe}$, and V. This is highlighted in Figure 2 which shows the fraction of the overall measurement uncertainty contributed by uncertainty in the isotopic composition of the sample being measured [25]. As expected from the data in Figure 1, this contribution is very significant for $\mathrm{Pb}$, notable for $\mathrm{Hg}$, $\mathrm{Cd}$ and possibly $\mathrm{Cu}$, and insignificant for all other elements.

The summary uncertainty budget presented in Figures 1 and 2 (and the measurement equation from which this has been developed) is only valid if the abundance of the isotope used for quantification in the calibration standards also falls within this range allowed for the samples. If it does not, then an additional uncertainty contribution, or a correction factor, may need to be applied. This is not something that may be taken for granted since the calibration standards may often have been prepared from isotopically enriched pure materials, and must be measured in order to determine whether an increase in the uncertainty estimate for the overall determination was required. The results of the determination of the isotopic composition of the calibration standards used are shown in Figures 3(a) and 3(b) which show that the majority of isotopes demonstrated good agreement between the measured value and the expected range of isotopic abundances. Table 1 highlights the level of this agreement for the isotopes used for quantification. 

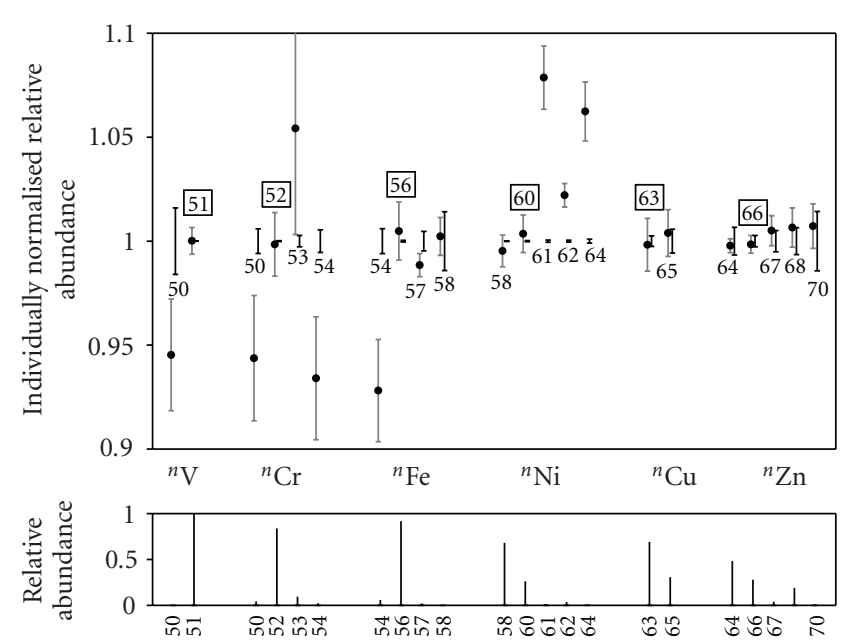

(a)
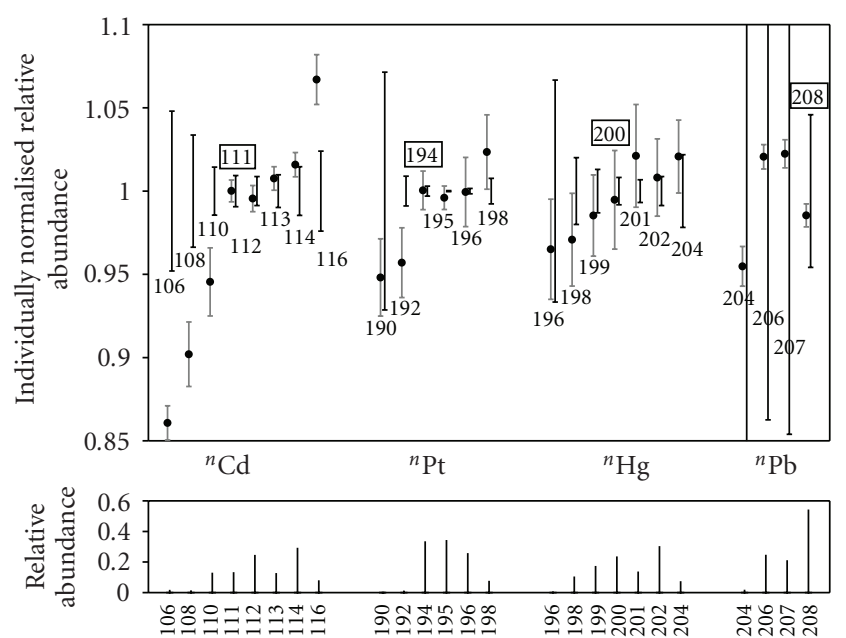

(b)

Figure 3: (a) V, Cr, Fe, Ni, Cu, and Zn: comparison of the measured relative isotopic abundance of the calibration standards (black circles, with the grey bars representing the standard error of the mean) against the expected range in natural, or representative, isotopic compositions (whichever is the larger range) (black bars). The relative atomic mass number is displayed for each isotope, with the boxed number being the isotope used for the quantification of the samples. Values are normalised to the centre of the natural (or representative) composition range for each isotope. The relative abundance is displayed for each element in the separate plot beneath the main chart. (b) $\mathrm{Cd}$, $\mathrm{Pt}$, $\mathrm{Hg}$, and $\mathrm{Pb}$ : comparison of the measured relative isotopic abundance of the calibration standards (black circles, with the grey bars representing the standard error of the mean) against the expected range in natural, or representative, isotopic compositions (whichever is the larger range) (black bars). The relative atomic mass number is displayed for each isotope, with the boxed number being the isotope used for the quantification of the samples. Values are normalised to the centre of the natural (or representative) composition range for each isotope. The relative abundance is displayed for each element in the separate plot beneath the main chart.

TABle 1: Agreement between the measured abundances for the isotopes used for quantifications and the expected abundance ranges.

\begin{tabular}{lc}
\hline Isotope used for quantification & Agreement with predicted range \\
\hline${ }^{50} \mathrm{~V}$ & No $+0.01 \%$ \\
${ }^{52} \mathrm{Cr}$ & No, $-0.1 \%$ \\
${ }^{56} \mathrm{Fe}$ & No, $+0.4 \%$ \\
${ }^{60} \mathrm{Ni}$ & No, $+0.3 \%$ \\
${ }^{63} \mathrm{Cu}$ & Yes \\
${ }^{66} \mathrm{Zn}$ & Yes \\
${ }^{111} \mathrm{Cd}$ & Yes \\
${ }^{194} \mathrm{Pt}$ & Yes \\
${ }^{200} \mathrm{Hg}$ & Yes \\
${ }^{208} \mathrm{~Pb}$ & Yes \\
\hline
\end{tabular}

Where there is agreement with the predicted range, we may assume that the uncertainty budget for the measurement already covers the expected range of isotopic compositions for both sample and calibration standard. Where Table 1 shows a lack of agreement, an additional component of uncertainty equal to the discrepancy in agreement needs to be added to justify the uncertainty statement. Given the large overall measurement uncertainties reported for the measurement of metal mass concentration in ambient air, these small additional uncertainty components are unlikely to increase the overall uncertainty of the measurement significantly. (An additional component of uncertainty has

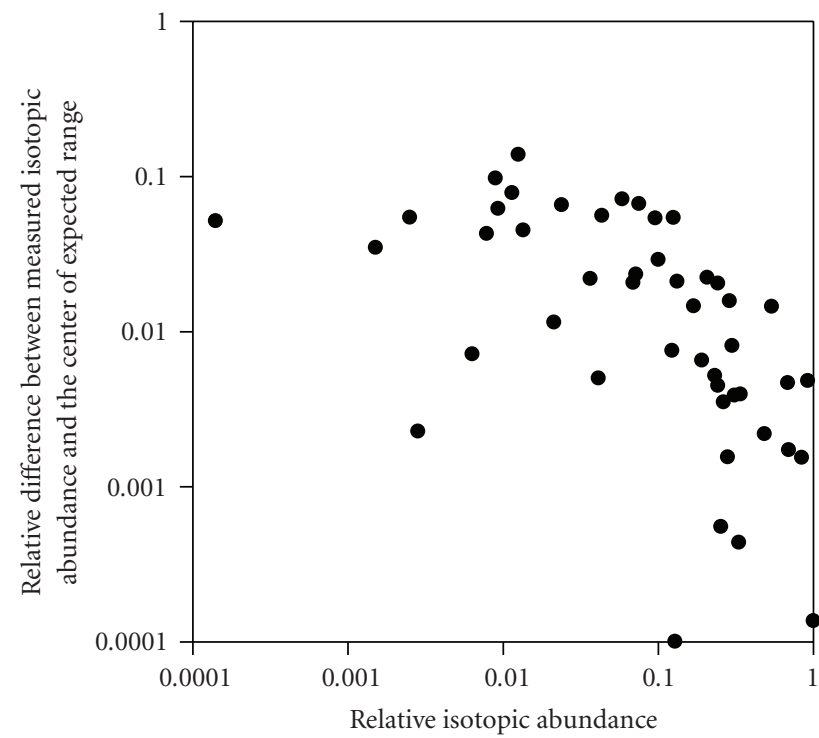

FIGURE 4: The relationship between the relative isotopic abundance of all the isotopes considered and the relative difference between the measured isotopic abundance and the centre of the expected range of isotopic abundance.

been added, rather than adding a term into the uncertainty budget to correct for bias, since in all cases the standard error of the mean of the isotopic composition measurements is greater than the observed disagreement in all cases, and 
thus a bias correction term is not justified.) Perhaps not surprisingly, Table 1 highlights that a disagreement was found for the elements with the smallest predicted range of isotopic compositions, where the accuracy of the isotopic measurement is more critical.

A brief inspection of Figures 3(a) and 3(b) suggests that the bias between the measured isotopic abundance and the centre of the expected range of isotopic abundances shows some tendency to increase as the isotopic abundance decreases. This relationship is plotted in Figure 4. Since the isotopes used for quantification are generally ones with high abundances, little attention is usually paid to the less abundant isotopes, and therefore, there may well be more bias in these measurements owing to unresolved interferences, unresolved detector nonlinearity, and instrument instabilities which have a larger proportional effect on the measurement results than for high abundance species.

\section{CONCLUSIONS}

A summary of the main sources of uncertainty encountered during the analysis of the mass concentration of metals in ambient air as part of the operation of the UK Heavy Metals Monitoring Network has been presented. It has been observed that the uncertainty contribution from possible variations in the isotopic composition of the sample depends on the element in question, but can be significant (as in the cases of $\mathrm{Pb}, \mathrm{Cd}$, and $\mathrm{Hg}$ ). The working curve method for the ICP-MS analysis of metals in solution, with a low resolution, high throughput instrument measuring at one $m / z$ ratio per element relies on the relative abundance of the isotopes under consideration being the same in both the sample and the calibration solution. Calculation of the uncertainty in this analysis assumes that the isotopic composition variation within the sample and calibration solution is limited to a defined range.

The results of the isotopic analysis of these calibration standards have shown that the isotopic composition of the calibration standards agrees with the expected range of isotopic comparisons in the samples for all but four elements. In these cases, additional uncertainty components were required to be added to the uncertainty budget to account for this bias, although the increase in the overall uncertainty of the measurement was not significant. It is interesting to note that the isotopic composition with respect to the other isotopes not under consideration not used for quantification has no effect, in theory, on the measurement.

The bias between the measured isotopic abundance and the centre of the expected range of isotopic abundances shows some tendency to increase as the isotopic abundance decreases. It has been suggested that since the isotopes used for quantification are generally ones with high abundance and little attention is paid to the lower abundance isotopes, the bias in these measurements may well be due to unresolved interferences, unresolved detector nonlinearity, and instrument instability which have a larger proportional effect on the measurement results than for high abundance species.

In future, it may be expeditious to determine more rigorously the isotopic composition of samples collected across the "network" so that the uncertainty contribution from $\delta_{X}$ for the elements where this is most significant (in particular $\mathrm{Pb}$ ) may be reduced, thereby reducing the overall measurement uncertainty.

\section{ACKNOWLEDGMENTS}

Useful discussions with Dr. Henrik Skov from the National Environmental Research Institute (DMU, Denmark) are gratefully acknowledged. The UK Department for Innovation, University and Skills' funding of the National Measurement System Chemical and Biological Metrology Programme, and the UK Department for Environment, Food and Rural Affairs' funding of NPL's operation and management of the UK Heavy Metals Monitoring Network, are both gratefully acknowledged.

\section{REFERENCES}

[1] "Ambient air pollution by As, Cd and Ni compounds, position paper. Brussels: working group on As, Cd and Ni compounds," European Commission DG Environment, Brussels, Belgium, 2000.

[2] "Council Directive 1999/30/EC of 22 April 1999 relating to limit values for sulphur dioxide, nitrogen dioxide and oxides of nitrogen, particulate matter and lead in ambient air," Official Journal of the European Union, vol. L163, pp. 41-60, 1999.

[3] "Council Directive 2004/107/EC of the European Parliament and of the Council of 15 December 2004 relating to arsenic, cadmium, mercury, nickel and polycyclic aromatic hydrocarbons in ambient air," Official Journal of the European Union, vol. L023, pp. 3-16, 2005.

[4] R. J. C. Brown, "The use and abuse of limits of detection in environmental analytical chemistry," The ScientificWorldJOURNAL, vol. 8, pp. 796-801, 2008.

[5] R. J. C. Brown, R. E. Yardley, D. Muhunthan, et al., "Twentyfive years of nationwide ambient metals measurement in the United Kingdom: concentration levels and trends," Environmental Monitoring and Assessment, vol. 142, no. 1-3, pp. 127140, 2008.

[6] EN 12341:1999 Air quality, "Determination of the PM10 fraction of suspended particulate matter. Reference method and field test procedure to demonstrate reference equivalence of measurement methods," CEN, Brussels, Belgium, 1999.

[7] R. J. C. Brown, D. Hood, and A. S. Brown, "On the optimum sampling time for the measurement of pollutants in ambient air," Journal of Automated Methods and Management in Chemistry, vol. 2008, Article ID 814715, 6 pages, 2008.

[8] EN 14902:2005, "Ambient air quality-standard method for the measurement of $\mathrm{Pb}, \mathrm{Cd}, \mathrm{As}$ and $\mathrm{Ni}$ in the PM10 fraction of suspended particulate matter," CEN, Brussels, Belgium, 2005.

[9] R. J. C. Brown, R. E. Yardley, A. S. Brown, and M. J. T. Milton, "Sample matrix and critical interference effects on the recovery and accuracy of concentration measurements of arsenic in ambient particulate samples using ICP-MS," Journal of Analytical Atomic Spectrometry, vol. 19, no. 5, pp. 703-705, 2004.

[10] A. S. Brown and R. J. C. Brown, "A study of the critical uncertainty contributions in the analysis of PCBs in ambient air," Journal of Automated Methods and Management in Chemistry, vol. 2008, Article ID 179498, 14 pages, 2008. 
[11] S. M. Nelms, C. R. Quétel, T. Prohaska, J. Vogl, and P. D. P. Taylor, "Evaluation of detector dead time calculation models for ICP-MS," Journal of Analytical Atomic Spectrometry, vol. 16, no. 4, pp. 333-338, 2001.

[12] I. M. Smith and F. O. Onakunle, "XLGENLINE version 1.0, document CMSC/M/06/657,” NPL, Teddington, UK, 2007.

[13] J. Vogl, "Characterisation of reference materials by isotope dilution mass spectrometry," Journal of Analytical Atomic Spectrometry, vol. 22, no. 5, pp. 475-492, 2007.

[14] Y.-C. Yip, J. C.-W. Lam, and W.-F. Tong, "Applications of lead isotope ratio measurements," Trends in Analytical Chemistry, vol. 27 , no. 5 , pp. 460-480, 2008.

[15] ISO Guide 98:1995, "Guide to the expression of uncertainty in measurement (GUM),” ISO, Geneva, Switzerland, 1995.

[16] M. J. T. Milton and R. I. Wielgosz, "Use of the international system of units (SI) in isotope ratio mass spectrometry," Rapid Communications in Mass Spectrometry, vol. 16, no. 23, pp. 2201-2204, 2002.

[17] J. K. Böhlke, J. R. de Laeter, P. de Bièvre, et al., "Isotopic compositions of the elements, 2001," Journal of Physical and Chemical Reference Data, vol. 34, no. 1, pp. 57-67, 2005.

[18] T. B. Coplen, J. K. Böhlke, P. de Bièvre, et al., "Isotopeabundance variations of selected elements (IUPAC technical report)," Pure and Applied Chemistry, vol. 74, no. 10, pp. 19872017, 2002.

[19] N. C. Munksgaard and D. L. Parry, "Lead isotope ratios determined by ICP-MS: monitoring of mining-derived metal particulates in atmospheric fallout, Northern Territory, Australia," Science of the Total Environment, vol. 217, no. 1-2, pp. 113-125, 1998.

[20] S.-C. Hsu, S. C. Liu, W.-L. Jeng, et al., "Lead isotope ratios in ambient aerosols from Taipei, Taiwan: identifying long-range transport of airborne $\mathrm{Pb}$ from the Yangtze Delta," Atmospheric Environment, vol. 40, no. 28, pp. 5393-5404, 2006.

[21] C. S. L. Lee, X.-D. Li, G. Zhang, J. Li, A.-J. Ding, and T. Wang, "Heavy metals and $\mathrm{Pb}$ isotopic composition of aerosols in urban and suburban areas of Hong Kong and Guangzhou, South China-evidence of the long-range transport of air contaminants," Atmospheric Environment, vol. 41, no. 2, pp. 432-447, 2007.

[22] J. Zheng, M. Tan, Y. Shibata, et al., "Characteristics of lead isotope ratios and elemental concentrations in PM10 fraction of airborne particulate matter in Shanghai after the phase-out of leaded gasoline," Atmospheric Environment, vol. 38, no. 8, pp. 1191-1200, 2004.

[23] N. Mattielli, J. Rimetz, J. Petit, et al., "Zn-Cu isotopic study and speciation of airborne metal particles within a 5-km zone of a lead/zinc smelter," Geochimica et Cosmochimica Acta, vol. 70, no. 18, supplement 1, p. A401, 1996.

[24] M. L. Geagea, P. Stille, F. Gauthier-Lafaye, and M. Millet, "Tracing of industrial aerosol sources in an urban environment using $\mathrm{Pb}, \mathrm{Sr}$, and $\mathrm{Nd}$ isotopes," Environmental Science and Technology, vol. 42, no. 3, pp. 692-698, 2008.

[25] R. J. C. Brown, D. M. Butterfield, S. L. Goddard, D. Muhunthan, M. Williams, and R. E. Yardley, "NPL Report AS20: Report to the Department of Environment, Food and Rural Affairs by the National Physical Laboratory: Annual Report for 2007 on the UK Heavy Metals Monitoring Network," NPL, Teddington, UK, 2008. 


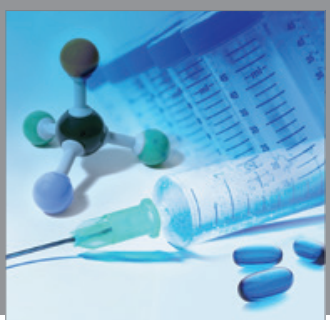

International Journal of

Medicinal Chemistry

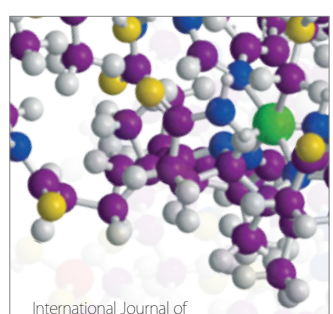

Carbohydrate Chemistry

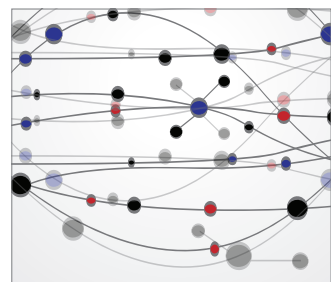

The Scientific World Journal
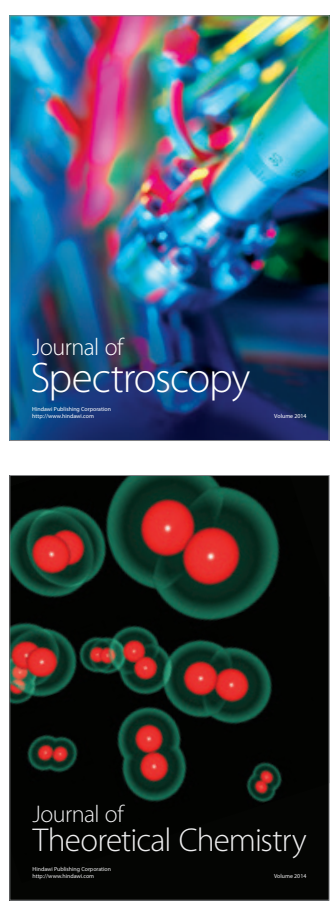
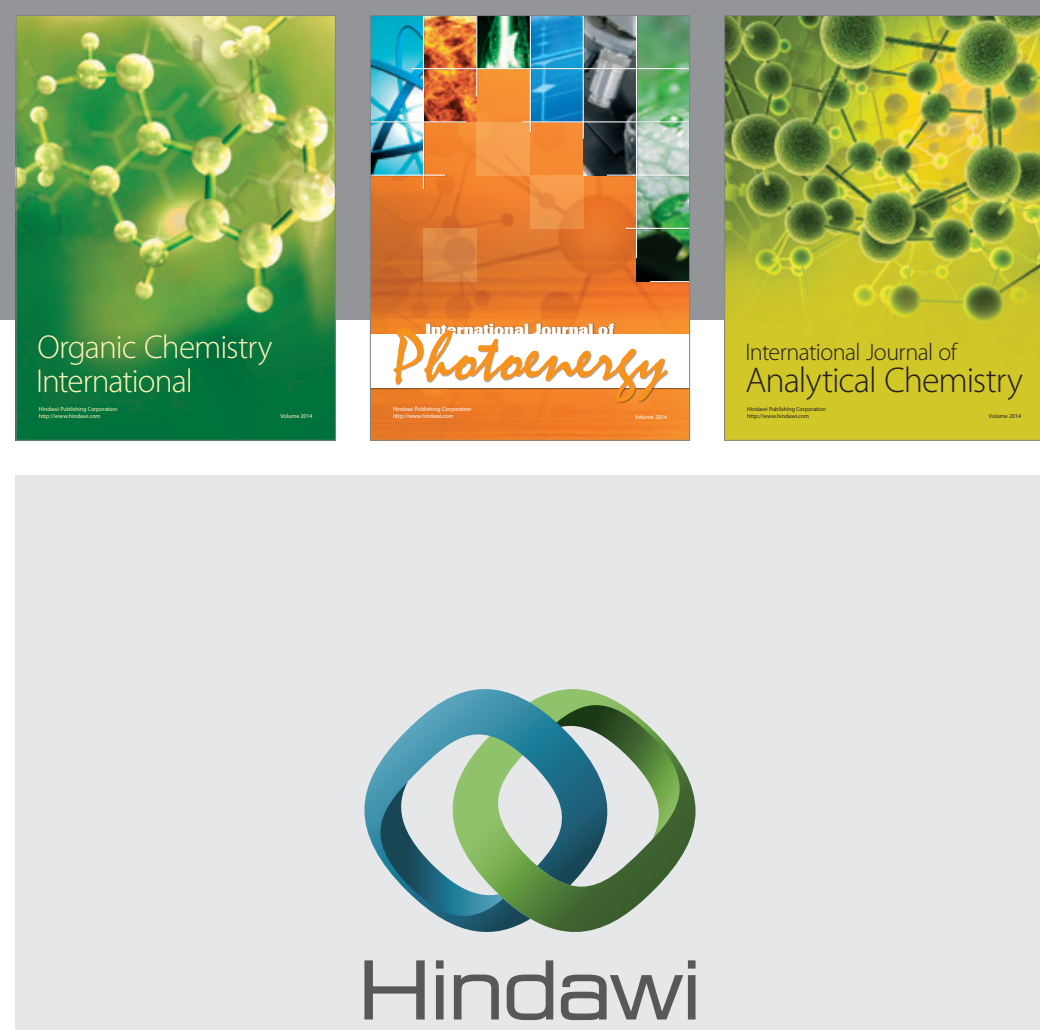

Submit your manuscripts at

http://www.hindawi.com
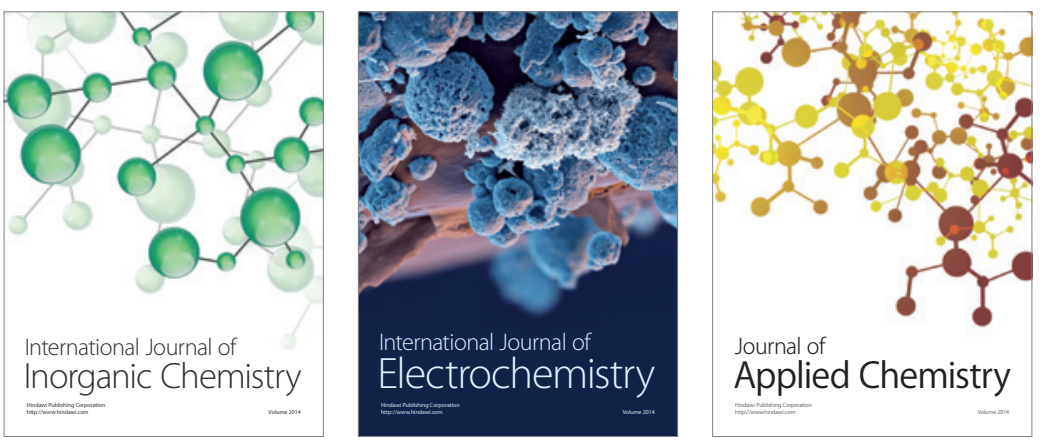

Journal of

Applied Chemistry
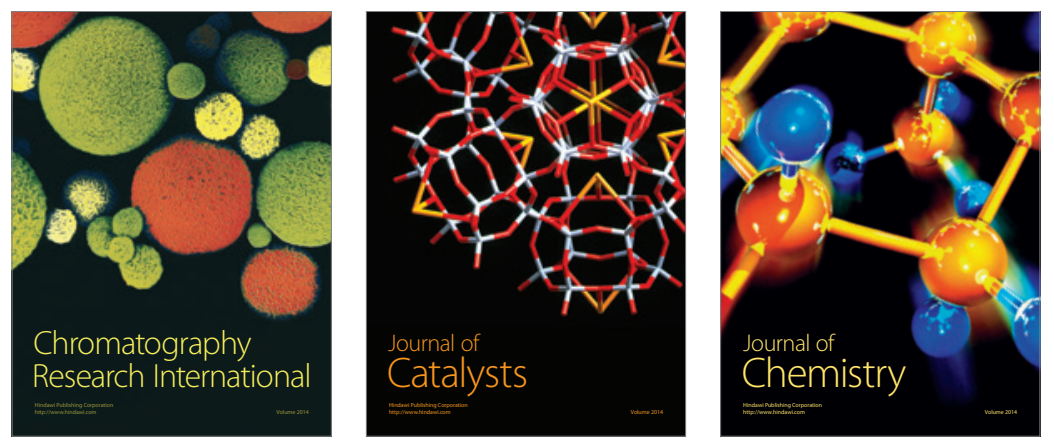
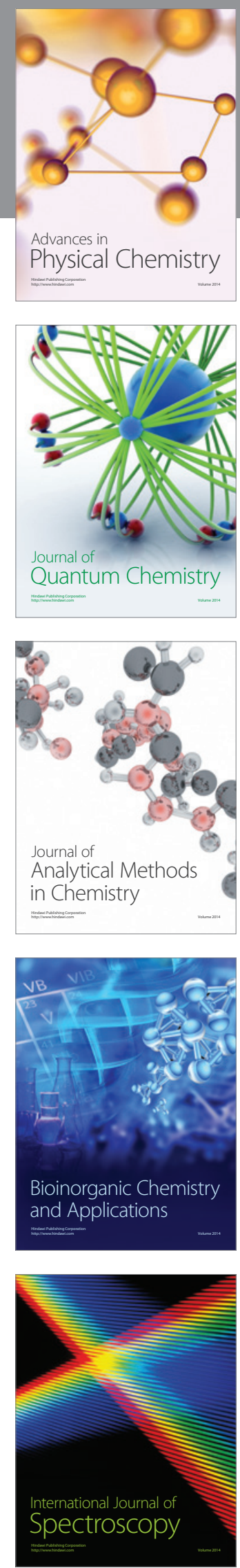